\title{
CiUdAdANÍA Y TRANSFORMACIÓN SOCIAL EN LA SOCIEDAD MEDIATIZADA
}

\author{
Patricia Mata Benito \\ Universidad Nacional de Educación a Distancia (UNED)
}

\section{Belén Ballesteros Velázquez \\ Universidad Nacional de Educación a Distancia (UNED)}

RESUMEN: La práctica de la ciudadanía encuentra en los medios tanto limitaciones como un espacio de posibilidades para la participación y el cambio. La falta de crítica ante la ingente cantidad de información deriva en un riesgo de adoctrinamiento y en la dificultad de construir imágenes alternativas. Nuestra reflexión, a partir del análisis de los discursos de informantes con amplia trayectoria en participación ciudadana, advierte de estos riesgos a la vez que señala otros usos que pueden aproximarnos hacia una ciudadanía crítica, participativa y orientada a la transformación social.

Los ejemplos que recogemos —radio comunitaria y vídeo participativoreflejan su valor como proceso y su interés por implicar a las personas y grupos como productores de información, facilitando experiencias de apropiación de los medios. Ésta debiera ser la orientación para el desarrollo de una educación mediática necesaria para el aprendizaje y la práctica de la ciudadanía.

Palabras ClaVe: medios de comunicación, ciudadanía, participación social.

RESUM: La pràctica de la ciutadania troba als mitjans tant limitacions com un espai de possibilitats per a la participació i el canvi. La falta de crítica davant la ingent quantitat d'informació deriva en un risc d'adoctrinament $\mathrm{i}$ en la dificultat de construir imatges alternatives. La nostra reflexió, des de l'anàlisi dels discursos d'informants amb una gran trajectòria en participació ciutadana, adverteix d'aquests riscos, alhora que assenyala altres usos que 
poden aproximar-nos a una ciutadania crítica, participativa i orientada a la transformació social.

Els exemples recollits — ràdio comunitària i vídeo participatiu— reflecteixen el valor com a procés i l'interès per a implicar-hi les persones i els grups com a productors d'informació. Es faciliten experiències d'apropiació dels mitjans. Aquesta hauria de ser l'orientació per al desenvolupament d'una educació mediàtica necessària per a l'aprenentatge i la pràctica de la ciutadania.

Paraules clau: mitjans de comunicació, ciutadania, participació social.

ABSTRACT: The media can be considered either as barriers or as potential spaces for participation and exchange where citizenship practices are concerned. The lack of criticism of the massive amounts of information gives rise to a risk of indoctrination and is an obstacle to building alternatives. Our reflection, based on an analysis of the discourses of citizens with a wide experience in participation, warns of these risks and shows other ways the media can be used to help develop a critical, participative and transformative citizenship.

The examples we describe-community radio and participatory video-involve people and groups in producing their own information. This should be the way forward to develop the critical media education needed for citizenship learning and practice.

KEYWORDS: media, citizenship, social participation.

$\mathrm{U}$

n eslogan publicitario omnipresente en nuestro entorno transmite la idea de que la tecnología digital pone el mundo al alcance de un solo dedo. La imagen es indudablemente atractiva, evoca un acceso fácil e ilimitado a todo tipo de oportunidades de relación, de comunicación, de información, de conocimiento. El lenguaje de las redes y de las conexiones se ha convertido en una metáfora tan potente que se utiliza incluso en el análisis de las relaciones no mediadas por la tecnología (Rendueles, 2013). Así, son muchas las voces que señalan que los medios han dejado de concebirse como instru- 
mento para convertirse en un entorno de socialización: lo que hace Internet es procesar la virtualidad y transformarla en nuestra realidad, constituyendo la «sociedad red», que es la sociedad en que vivimos, señala Castells (s/f). Esta afirmación, sin embargo, puede problematizarse. Lo cierto es que, pese a la omnipresencia de la red en nuestras vidas, cada vez más mediatizadas, no dejamos de habitar los territorios físicos en los que se desarrolla nuestra vida cotidiana. El mismo análisis de Castells incide en la idea de que la sociabilidad virtual no hace más que reproducir la que se produce en el mundo «real», añadiendo únicamente ciertos factores no permanentes, como la inmediatez y la intensidad.

El abordaje educativo, desde una perspectiva crítica, de las implicaciones de la mediatización progresiva de la sociabilidad, se revela urgente. En un escenario de enfrentamiento entre «apocalípticos» e «integrados» (Linde Navas, 2009), los esfuerzos educativos se están orientando prioritariamente a la extensión y mejora del acceso a los medios, relegando a un segundo plano la reflexión profunda sobre sus oportunidades y sus amenazas. Esta cuestión emerge con fuerza en el curso de un proyecto de investigación orientado a la formulación de propuestas educativas favorecedoras del aprendizaje y la práctica de una ciudadanía que caracterizamos como crítica, participativa y transformadora, que llevamos a cabo entre los años 2009 y 2012. A través de entrevistas en profundidad, historias de vida y un vídeo-investigación participativo, nos propusimos explorar los discursos y las experiencias de ciudadanas y ciudadanos comprometidos con la mejora de sus entornos y la transformación social. En ellos, el papel relevante de los medios en la construcción de la ciudadanía aparece como una preocupación compartida por la mayor parte de las personas que han participado en nuestro estudio. Sus aportaciones inciden en señalar los riesgos, pero también las oportunidades de cambio y mejora de las comunidades que una utilización crítica de los medios puede ofrecer.

\section{Riesgos y oportunidades para un uso crítico de los medios}

Algunos efectos de la revolución mediática se perciben como limitadores del ejercicio de la ciudadanía. La desinformación provocada por el torrente 
descontrolado de información sin filtrar es uno de los efectos más señalados. Así expresaba esta idea un militante político:

En el mundo de la información nos hemos convertido en personas desinformadas, porque hay tanto, que nadie es capaz de diferenciar ni de filtrar [...] porque la información está ahí, pero es tan difícil llegar porque hay tanta, que muchas veces no sabes lo que pasa. (E15)

Ramonet (2011) destaca la multidireccionalidad de la información, que fluye ahora en todos los sentidos, vertical, circular y horizontalmente. Se impone una nueva lógica de work in progress, que no concibe la información como un producto terminado sino como un proceso dinámico, un diálogo. Esta aparente democratización de la información, sin embargo, puede dar lugar tanto a una sabiduría colectiva como a un embrutecimiento generalizado, convirtiendo a los humanos en «ignorantes saturados de información».

Los medios se perciben también como productores y reproductores de una sociedad que se dibuja como individualista y fuertemente consumista. Mediante la utilización de estrategias de desinformación y manipulación contribuyen a construir un clima de apatía, impotencia y desconfianza que desempodera a los ciudadanos y a las ciudadanas. La sobreabundancia de información sin filtrar genera un ruido excesivo que oculta los mensajes significativos. Para una de nuestras participantes, profesora de educación secundaria: «de todo lo que somos educados en un día, el ochenta por ciento tiene que ver, con las imágenes, con los medios [...] todos son mensajes en un sentido, y hacia unos determinados valores, hacia una determinada concepción de la ciudadanía en tanto que, en tanto que... consumo» (E7).

Preocupa también la transformación de los espacios tradicionales de relación en una sociedad mediatizada. Se percibe un cambio positivo en el hecho de que los vínculos basados en identidades y territorios sean sustituidos por otro tipo de identificaciones relacionadas con intereses, expectativas o experiencias comunes. Surgen así nuevas formas colaborativas que favorecen formas de participación diferentes, orientadas a la visibilización y legitimación de identidades diversas, estilos de vida alternativos, visiones del mundo que no se pretenden modelos únicos: 
Cada vez hay, más peso de las redes sociales [...] personas, grupos, con problemas juntos que resolver, eh, formas colaborativas de... de solucionar sus experiencias de vida, y yo creo que eso le está dando un cambio a la sociedad. (E21)

Las redes sociales, identidades de orientación sexual, identidades basadas en gustos musicales, formas artísticas, por tanto, es... podemos decir que las formas de participación son diferentes [...] es el mayor cambio, las tecnologías de última generación que han sustituido a las grandes metanarrativas, metanarrativas que desaparecieron en cuanto elemento fundamental de movilización para la participación. (E11)

Es indudable que el mundo virtual está cambiando nuestra concepción espacio-temporal; la posibilidad de establecer relaciones próximas con personas físicamente distantes está presente en la vida cotidiana de muchas personas. No obstante, este hecho no implica de forma automática una sociabilidad más densa. No sólo por los nuevos factores de exclusión (o desconexión) que acompañan al desarrollo tecnológico, sino también por la fragilidad de las redes y comunidades virtuales, y su tendencia a la homogeneización. Sunstein (2003) señala la amenaza que implican para la propia democracia las posibilidades ilimitadas de filtración que ofrecen las tecnologías, y que permiten configurar una especie de «mundo a medida» del consumidor: éste puede fácilmente seleccionar entre multitud de medios, canales o redes aquellos que responden a sus preferencias, aislándose de cualquier contacto con experiencias o puntos de vista divergentes.

Las nuevas comunidades y redes afrontan, además, el desafío de no reproducir las barreras y los procesos de exclusión que han acompañado tradicionalmente a la configuración de los colectivos. En este sentido, se valora la flexibilidad de los vínculos sociales que se generan en la red: «ahora la gran cuestión es si este límite, esta forma exclusivista, autoritaria, si es... cómo decir, conservadora, o si también puede ser plástica, porosa, flexible» (E12). Si bien la plasticidad de las relaciones aporta elementos positivos al desafiar los fundamentalismos identitarios, puede también contribuir a la fragilidad y precariedad de los vínculos sociales, como indica Bauman (2003) y a la desactivación del proyecto de una ciudadanía transformadora. 
En los territorios físicos, la conciencia de una cierta pérdida del sentido de los vínculos comunitarios está impulsando también el desarrollo de proyectos ciudadanos en entornos micro, como barrios y municipios, que se construyen desde nuevas lógicas en espacios sociales innovadores, como los centros sociales, o renovados, como las asociaciones vecinales. El denominador común de esos lugares incide también en la apertura, la inclusión sin reservas de personas y colectivos en un proyecto común a construir:

Estamos ahora intentando construir un centro que queremos llamar la Casa del Barrio, que sería un lugar de encuentro entre todos los colectivos y personas [...] que sea un centro asambleario, donde todo el mundo del barrio pueda aportar sus ideas $[\ldots]$ donde... se pueda construir algo colectivo. (E5)

Si la sociabilidad afronta desafíos similares en la red y en el mundo real, ¿cómo hacer confluir las prácticas ciudadanas que se desarrollan en ambos espacios? Algunas de las personas que han participado en nuestro estudio han compartido con nosotras experiencias educativas de empoderamiento de la ciudadanía a través del desarrollo de competencias mediáticas. Se trata de hacer ecología de la información, lo cual implica tanto el análisis crítico de la información existente como la capacidad de crear y difundir informaciones propias a través de diversos medios, incluidos los audiovisuales.

\section{Experiencias de apropiación mediática}

En los medios de comunicación, si realmente dejamos de tratar a los usuarios como padres que les enseñen a sus hijos/as, no sé, si les dejamos... entrar a los usuarios, y eh... provocamos también debates sanos, no debates, eh, altisonantes, no debates encrespados, no debates que conduzcan a la polarización de posturas, yo creo que tenemos muchísima responsabilidad. Y yo siempre eh... cada vez que tengo oportunidad en la comunidad de los medios de comunicación, eh, apuesto por la reflexión, porque las noticias no sean... 28 flashazos que nos llegan en un día, sino que pensemos en ellas como algo que construye la sociedad o que ayuda a la sociedad cada vez a tomar mejores decisiones. (E21)

La necesidad de una alfabetización mediática es subrayada como medio y escenario de experiencia de ciudadanía. Necesitamos una educación que nos capacite para la lectura y el debate críticos. Una educación que promueva 
apropiarnos de los medios de comunicación como lenguaje que nos pertenece, con el que poder construir otras imágenes y otras alternativas de cambio social.

Como recogen Gonzálvez y Contreras Pulido (2014), la UNESCO viene desarrollando sucesivas recomendaciones para que los estados adopten medidas que faciliten la educación mediática en el ámbito de la educación formal y permanente (Declaración de Grundwald, 1982; Agenda de París, 2007; Declaración de Braga, 2011), considerando la educación en medios como una forma de empoderamiento social y contribución a la ciudadanía autónoma. El Parlamento Europeo (2008) destaca igualmente el papel de la educación mediática como forma de educación política, instando su desarrollo a través de las escuelas, como elemento de formación de profesores y entre las personas mayores.

Estas recomendaciones han tenido un escaso eco en nuestro país desde los organismos e instituciones responsables. Los medios de comunicación son una forma de control social; los gobiernos están interesados en la instrumentalización de los medios al servicio de sus propios intereses, y consideran un riesgo la apertura a la participación social en la producción de información. Consecuentemente, la educación mediática ha sido prácticamente invisibilizada en la educación formal, quedando únicamente relegada a experiencias que surgen desde el compromiso del profesorado, sin obedecer a ninguna necesidad marcada desde el currículo escolar.

Es en el ámbito de la educación continua donde encontramos experiencias de formación para la comprensión y para la producción crítica de la información, desde la participación y el diálogo. Su análisis nos sitúa en el enfoque de la comunicación para el cambio social, en la medida en que los actores sociales, comunicadores, participan en un proceso de crecimiento colectivo que adquiere una relevancia mayor que el propio mensaje o producto final (Gumucio-Dagron, 2011).

[...] y el ejemplo sería con mujeres de la escuela de adultos de Barakaldo, que además son mujeres mayores; a las mujeres mayores mucha voz, así con autoridad y que se les respete y que se les escuche, no se les suele dar... o sea, no aparecen muchas mujeres mayores en los medios contando cómo ven ellas las cosas. Entonces, el proceso que hemos tenido de capacitación para que pudieran 
llegar no solamente a hacer un vídeo sino para que se dieran cuenta de que lo que tienen que contar o lo que reflexionan o lo que piensan es importante también, claro, pues era un proceso muy interesante. $\mathrm{Y}$ a partir de eso, de que vieran con sus reflexiones lo que tenían que contar, reflexionar también cómo se representa a las mujeres en los medios audiovisuales en general, en el cine incluido, y a partir de ahí crearan su discurso, pues ha sido muy interesante [...] no es sólo una cuestión técnica. No es únicamente, «mira, así se coge una cámara, así se hace esto», no, incluso mucho más de que reflexionaran sobre su experiencia y vieran que lo que tienen que decir es interesante y la gente tiene que aprender de esas experiencias, ¿no? El hecho de que no se las escuche, porque los medios tradicionales no las quieran escuchar, no quiere decir que no tengan nada que decir, ¿no? [...] valoraron al final del curso como que habían adquirido una capacidad de comunicarse que no tenían.

[...] hay transformación, porque esa gente está siendo escuchada por otra cuando cogen un vídeo, una radio... y difunden un mensaje que quieren contar, ¿no?, de cómo ven ellas el mundo. Eso significa que se fomenta que la gente sea activa y participativa, que sea una ciudadanía más... activa. (E16)

Como señala esta informante, la radio comunitaria y el vídeo participativo son experiencias en las que se vinculan ciudadanía y medios. La radio comunitaria se ha venido desarrollando desde los años 70 en América Latina, desde las iniciativas de educación popular que se apoyan en la pedagogía de Freire, Díaz Bordenave y Kaplún. Estos pensadores apoyarán la necesidad de trabajar desde modelos educativos que enfaticen en el proceso, más que en contenidos o productos, que faciliten la posibilidad de tener plena participación en la comunicación (Ventura, 2007).

La Asociación Mundial de Radios Comunitarias (AMARC, 1998) viene definiendo el objetivo de las mismas, no siendo tanto hacer algo por la comunidad como promover que la comunidad haga algo por ella misma, como por ejemplo poseer el control de su propio medio de comunicación.

En proyectos anteriores hemos recogido voces que narran la experiencia de participación en medios. La entrevista realizada por una de nosotras (Ballesteros, 2010) al promotor de RVK Radio Vallekas, muestra la valoración de este proyecto en el barrio: 
Si le preguntas a la gente, lo valoran muy bien, aunque sí hay que decir que antes participaban más y eran más reivindicativos [...]. La emisora está dentro de una red, la Red con voz, que es un espacio dentro de la comunicación radiofónica comunitaria para democratizar la información y favorecer el intercambio de propuestas, planteamientos, denuncias, proyectos... Para Radio Vallekas es una manera de tener más fuerza y de que su proyecto asociativo vaya más allá de los límites del barrio. (p. 296)

Por su parte, las experiencias de vídeo participativo intentan rescatar un espacio de participación, adueñado por la industria de consumo para quienes únicamente contamos como audiencia. Lo audiovisual, como indican Montero y Moreno (2014), está siendo producido mayoritariamente desde la cultura del espectáculo, orientada al entretenimiento, la banalización y la negación del conflicto. En reacción, es necesario recuperar y hacer nuestros los espacios de expresión en los que podamos construir de forma colectiva y participante nuestras propias producciones. El vídeo participativo es, en palabras de estos autores, «un encuentro de emociones, un proceso de intervención, social..., una herramienta de movilización» (p. 66).

El colectivo de Cine sin Autor, como ejemplo, ha logrado desactivar los condicionamientos desde los que entendió el cine y ofrecer otro concepto abierto a la producción cinematográfica de otras personas y grupos: «Espectadores éramos. Espectadores de las operaciones financieras, de la gestión política. Espectadores de televisión. Espectadores de un concierto, de una performance, de un museo. Espectadores de un mundo diseñado y protagonizado por otros pocos. Muchas veces, espectadores de nuestra propia vida» (2013: 79).

Cine sin Autor renuncia a ser espectador; y renuncia también a la necesidad de buscar un nuevo espectador que legitime el sentido de lo producido. El sentido está en el proceso de expresión común. Su apuesta por una política de la colectividad permite que el cine constituya una actividad gestionada por los barrios, las asociaciones, las familias, los grupos. Todo el sistema audiovisual viene conformado por las colectividades sociales de cine, en colaboración con los profesionales que puedan adherirse a estos proyectos. La potencia cinematográfica de estos colectivos se basa en las relaciones intergrupales, 
sus vivencias comunes, su cercanía, a partir de las cuales expresarán su subjetividad en las narrativas audiovisuales.

Estas breves ilustraciones sobre los vínculos entre medios y experiencias de ciudadanía motivan algunas reflexiones sobre su sentido y alcance. Cuando analizamos los medios desde un enfoque de ciudadanía para la transformación social queremos dar valor a las pequeñas experiencias y cambios. A través de estas experiencias entramos en contacto con un sector crítico de profesionales que desde el interior de los medios se plantea su poder y su responsabilidad en la transformación social. Apuestan por la reflexión y por convertirse en vehículos transmisores de la voz de la ciudadanía, ayudando a las personas a pasar de meros receptores y consumidores, a productores de información. Inciden así en el potencial transformador de los medios y su capacidad para generar procesos de aprendizaje de la ciudadanía. Se constata la necesidad de incidir en la corresponsabilidad educativa de estos en un entorno de progresiva mediatización de las vidas de las personas.

Desde nuestra perspectiva es urgente no sólo reflexionar críticamente sobre el papel educativo de los medios, sino incluir la educación mediática como un contenido básico en todos los ámbitos educativos, y de forma específica en la educación obligatoria. Se trata de promover un aprendizaje que fomente el análisis crítico de los distintos tipos de mensajes y sus posibles manipulaciones (Linde Navas, 2009). Este aprendizaje mediático debe integrar audiovisuales, multimedia y también medios portadores de mensajes largos y complejos, como los libros: se trata de evitar que la capacidad multitarea potenciada por la red nos aleje de formas de pensamiento que exigen reflexión y concentración (Ramonet, 2011). Por otra parte, y dada la relevancia actual de la cultura visual, ha de incluir la «educación de la mirada» (García González, 2008; Pandora Mirabilia, 2009), una alfabetización audiovisual que implica comprender el papel que éstos están desempeñando actualmente en la construcción de la realidad social y aprender tanto a decodificar sus mensajes como a producir los propios, haciendo un uso crítico de los medios. 


\section{Referencias}

Amarc (1998): What is Community Radio, Amarc Africa and Panos Southern Africa. En: <http://www.amarc.org/documents/manuals/ What is CR english.pdf $>$.

Ballesteros Velázquez, B. (2010): «Educación y medios». En Aguado, T. (Coord.): Diversidad e igualdad en educación, pp. 277-316, UNED, Madrid.

Bauman, Z. (2003): Modernidad líquida, Fondo de Cultura Económica, México.

Castells, M. (s/f): Internet y la Sociedad Red. Disponible en: $<\underline{\text { http: } / / w w w . ~}$ uoc.edu/web/cat/articles/castells/castellsmain2.html $>$.

Colectivo Cine sin Autor (2013): «Cine XXI. La política de la colectividad. Manifiesto de Cine sin Autor». Arte y politicas de identidad, 8, pp. 13-27.

García González, A. (2008): Clases de cine. Compartir miradas en femenino y masculino. Instituto de la Mujer, Ministerio de Igualdad, Madrid.

Gozálvez, V. y P. Contreras (2014): «Empoderar a la ciudadanía mediática desde la educomunicación». Comunicar, 42, 129-136. [DOI: 10.3916/C42-2014-12]

Gumucio-Dagron, A. (2011): «Comunicación para el cambio social: clave del desarrollo participativo». Signo y pensamiento, 30, 58, 26-39.

Linde Navas, F. A. (2009): «¿Demonios o chivos expiatorios? (Sobre los efectos de los medios audiovisuales en el desarrollo cognitivo y moral)». En Rubio Carracedo, J.; J. M. Rosales y M. Toscano (dirs.): Democracia, ciudadanía y educación (pp. 253-276),Akal/Universidad Internacional de Andalucía, Madrid.

Montero Sánchez, D. y J.M. Moreno Domínguez (2014): El cambio social a través de las imágenes. Guía para entender y utilizar el vídeo participativo, Catarata, Madrid.

Pandora Mirabilia (2009): En plano corto. Guía para el uso del vídeo social en la educación para el desarrollo, ACSUR Las Segovias, Madrid.

Parlamento Europeo (2008): Resolución del 16 de diciembre sobre la alfabetización de los medios de comunicación en un mundo digital (2008/2129(INI). En: <http://www.europarl.europa.eu/sides/getDoc.do?pubRef=-//EP//TEXT+REPORT + A6-2008-0461+0+DO$\mathrm{C}+\mathrm{XML}+\mathrm{V} 0 / / \mathrm{ES} \#$ titlel $>$. 
RAMonet, I. (2011): La explosión del periodismo. De los medios de masas a la masa de medios, Clave Intelectual, Madrid.

Rendueles, C. (2013): Sociofobia. El cambio político en la era de la utopía digital, Capitán Swing, Madrid.

Sunstein, C. R. (2003): República.com. Internet, democracia y libertad, Paidós, Barcelona.

Ventura, G. C. (2007): «Educação para a cidadania via rádios comunitárias», Canadian Journal of Latin American \& Caribbean Studies, 32, 63, 167-289. 